Biomarkers

\title{
The role of immune PSA complex (iXip) in the prediction of prostate cancer
}

Riccardo Lombardo , Giorgia Tema , Fabiana Cancrini , Luca Albanesi , Luca Mavilla , Paola Tariciotti , Barbara Cristina Gentile , Pietro Aloisi , Giorgio Rizzo , Stefano Tardioli \& Roberto Giulianelli

To cite this article: Riccardo Lombardo , Giorgia Tema , Fabiana Cancrini , Luca Albanesi , Luca Mavilla , Paola Tariciotti , Barbara Cristina Gentile, Pietro Aloisi , Giorgio Rizzo, Stefano Tardioli \& Roberto Giulianelli (2020): The role of immune PSA complex (iXip) in the prediction of prostate cancer, Biomarkers, DOI: 10.1080/1354750X.2020.1841294

To link to this article: https://doi.org/10.1080/1354750X.2020.1841294

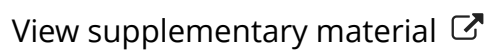

Accepted author version posted online: 26

Oct 2020.

Submit your article to this journal $\pi$

Q View related articles $\asymp$

View Crossmark data $₫$ 
The role of immune PSA complex (iXip) in the prediction of prostate cancer

Riccardo Lombardo, Giorgia Tema, Fabiana Cancrini, Luca Albanesi, Luca Mavilla, Paola Tariciotti, Barbara Cristina Gentile, Pietro Aloisi, Giorgio Rizzo, Stefano Tardioli, Roberto Giulianelli.

\section{Corresponding author:}

Giorgia Tema, M.D

Department of Urology

Casa di Cura Nuova Villa Claudia, C.U.r.A Group, Rome, Italy

Email:giorgiat88@hotmail.it 


\title{
ABSTRACT
}

PURPOSE: To analyze the performance of iXip in the prediction of prostate cancer (PCa) and high-grade prostate cancer.

METHODS: A consecutive series of men undergoing MRI/FUSION prostate biopsies were enrolled in one center. Indications for prostate biopsy included abnormal prostate specific antigen levels (PSA>4ng/ml) and/or abnormal digital rectal examination (DRE) and/or abnormal MRI. All patients underwent the evaluation of serum PSA-IgM concentration and the iXip ratio was calculated. Accuracy iXip for the prediction of prostate cancer was evaluated using multivariable binary regression analysis and receiver operator characteristics (ROC) curves.

RESULTS: Overall 160 patients with a median age of $65(62 / 73)$ years were enrolled. Overall, $42 \%$ patients were diagnosed with prostate cancer and $75 \%$ of them had highgrade cancer (Epstein $\geq 3$ ). Patients with prostate cancer were older and presented higher PSA levels, higher PIRADS scores and lower prostate volumes. On ROC analysis iXip presented an area under the curve (AUC) of 0,57 in the prediction of PCa and of 0,54 for the prediction of high-grade prostate cancer.

CONCLUSION: In our experience, immune PSA complexes are not predictors of PCa. iXip analysis should not be included in the diagnostic pathway of patients at increased risk of $\mathrm{PCa}$.

Keywords: Prostate cancer, biomarkers, high grade, iXip, immune-complex

\author{
Word Count:
}

Abstract: 183 
Text: 2704

\section{INTRODUCTION}

Prostate cancer $(\mathrm{PCa})$ is the second most frequently diagnosed cancer and the sixth leading cause of cancer death among men. Prostate specific antigen (PSA) remains the first line and most commonly used serum biomarker for the detection of PCa. Using a threshold of more than $4 \mathrm{ng} / \mathrm{ml}$, PSA test has an overall sensitivity of $21 \%$ and a specificity of $51-91 \%^{1,2}$. Additionally, in patients with a PSA $<4.0 \mathrm{ng} / \mathrm{ml}$ the negative predictive value of the test is $81 \%^{3}$.

An important limitation of PSA driven diagnosis is the high number of clinically insignificant PCa diagnosis. As a result, several patients will undergo unnecessary prostate biopsies, particularly in the PSA range of $4.0-10.0 \mathrm{ng} / \mathrm{ml}$, where prostate cancer is present in only $25 \%$ of men ${ }^{4}$. Prostate biopsies are associated with a small risk of morbidity ( infections, acute urinary retention, bleeding) in addition to being costly and uncomfortable for patients ${ }^{5}$

In the past years, several authors have focused on the development of PCa molecular biomarkers, like prostate cancer antigen 3 (PCA3) or circulating tumour cells (CTs) to improve the abovementioned limitations of PSA ${ }^{7}$. Although promising initial results, these biomarkers are limited by the lack of a specific cut-off value and their poor accuracy in early stages of the disease. Thus, discovery and validation of novel noninvasive PCa biomarkers is still an unmet need in PCa diagnosis.

Several studies have evaluated the role of complexes between cancer specific biomarkers and IgM in cancer diagnosis ${ }^{8-12}$. Some studies have suggested that PSAImmune complexes may have a role as a biomarker for PCa with promising results ${ }^{11,13-}$ 15. Very recently the EAU guidelines have recommended the use of algorythms 
including several PCa predictors (age, digital rectal examination, PSA, prostate volume, PIRADS score) to improve the detection of significant cancer. The iXip is automatic an algorithm including age, prostate volume, PSA, and PSA-IgM levels developed by Xeptagen to predict PCa risk, however very few studies have validated its clinical use. Moreover none of them include MRI data ${ }^{16}$.

Aim of our study was to evaluate the role of iXip in prostate cancer diagnosis in a cohort of patients undergoing MRI/FUSION prostate biopsies.

\section{MATERIALS AND METHODS}

\section{Study Population and Design}

From January 2018 to January 2020, patients referred to our prostate clinic with a PSA level $\geq 4 \mathrm{ng} / \mathrm{mL}$ were scheduled for prostate MRI and trans-perineal fusion prostate biopsies. All patients signed a dedicated informed consent, all the procedures were approved by the Local Ethics Committee and the study was conducted in accordance with the principles of the Declaration of Helsinki. We excluded from the study patients who had a history of prostate cancer or prostate surgery and patients with previous prostate biopsies.

Before the biopsy procedure, all patients underwent a detailed medical history (including family history of PCa, previous biopsies and comorbidities) and physical examination including digital rectal examination (DRE) performed by a senior staff urologist.

All patients underwent multiparametric (mp) 1,5 Tesla MRI before prostate biopsies. A single expert radiologist read the mpMRI and v2 PIRADS was used to grade prostate lesions (ST).

PSA testing and iXip calculation 
On the day of prostate biopsy, blood specimens were drawn before the procedure at 8:00 AM and total PSA levels were measured. Moreover, serum PSA-IgM concentration was measured in duplicate using Prostate-IC kit (XG007, Xeptagen SpA, Italy). The analysis with Prostate-IC kit was performed on an open and fully automated ELISA analyzer.

The iXip index was calculated as reported by Gallotta et $\mathrm{al}^{14}$. by using the online calculator available at http://ixip.xeptagen.com/(login required): age, prostate volume, PSA, and PSA-IgM levels of the patient were input in the calculator, and the iXip value (from 0 to 1 ) was provided immediately.

All patients underwent trans perineal-fusion biopsies using Aloka ultrasound equipment. Prostate volume (PV) was calculated using the ellipsoid formula. Patients underwent 4 cores per lesion in addition 5 random cores per lobe were taken. We used a 16G biopsy needle (Magnum 1000, BARD, Rome, Italy) and a dedicated spring loaded biopsy gun (MG1522, BARD). Antibiotic prophylaxis (periprocedure i.v. cefazolin 2g) and peri prostatic anesthetic block was performed according to our departmental $\operatorname{protocol}^{17,18}$.

High-grade disease was defined as ISUP Grade $\geq 3^{19}$. A single pathologist, who was blinded to the clinical data, except for age, was involved in the study.

\section{Statistical Analysis}

Statistical analysis was performed using the Statistical Package for the Social Sciences $\left(\mathrm{SPSS}^{\oplus}\right)$ version 24.0 software (SPSS Inc., IBM Corp., Armonk, NY, USA). Evaluation of data distribution, using the Kolmogorov-Smirnov test, showed a non-normal distribution of all the variables included in the study. Differences between groups of patients in medians for quantitative variables and differences in distributions for 
categorical variables were tested with the Mann-Whitney test and chi-squared test, respectively. Univariate and multivariate binary logistic regression were used to evaluate predictors of $\mathrm{PCa}$ and high grade $\mathrm{PCa}$. Receiver operator characteristic curves were used to evaluate the accuracy of iXip in the prediction of cancer and high-grade cancer.

\section{RESULTS}

Overall 160 patients with a median age of $65(62 / 73)$ years were enrolled. General characteristics of the cohort are listed in Table 1.

\section{Prostate cancer evaluation}

Overall, $42 \%$ patients were diagnosed with prostate cancer. Patients with prostate cancer were older ( 71 vs 64 years, $\mathrm{p}<0,05$ ), presented higher PSA levels( 6,9 vs 5,7 ng/ml, $\mathrm{p}<0,05$ ), higher PIRADS scores (PIRADS $\geq 429 \%$ vs $17 \%, p<0,05$ ) and lower prostate volumes ( $40 \mathrm{vs} 53 \mathrm{cc}, \mathrm{p}<0,05$ ). No significant differences in iXip values was recorded when comparing patients with and without PCa diagnosis. (Table 2). More specifically median iXip in PCa patients was 0,33 vs 0,29 in no cancer patients $(\mathrm{p}=0,182)$.

On univariate binary logistic regression analysis age $(1,07: 1,02-1,12 ; p=0,001), \operatorname{DRE}($ 2,03:,1,10-4,49; $\mathrm{p}=0,001), \quad$ PSA (1,06: 1,01-1,11; $\mathrm{p}=0,001), \quad$ PV $(0,98: 0,96-0,99$ $\mathrm{p}=0,001)$ and PIRADS score $(2,68: 1,22-5,89 ; \mathrm{p}=0,023)$ were predictors of PCa. On multivariate binary logistic regression age $(1,06: 1,01-1,11 ; \mathrm{p}=0,024)$, DRE $(2,34: 1,25$ 4,01; $\mathrm{p}=0,001), \mathrm{PV}(0,97: 0,95-0,99, \mathrm{p}=0,001)$ and PIRADS score $(2,45: 1,45$ $6,45 ; \mathrm{p}=0,001)$ were independent predictors of PCa. On ROC analysis iXip presented an AUC of 0,57 in the prediction of PCa. (Table 3) 


\section{High-grade cancer evaluation}

Overall, $75 \%$ patients were diagnosed with high-grade prostate cancer. Patients with high-grade prostate cancer were older ( 70 vs 68 years, $\mathrm{p}<0,10$ ), presented higher PSA levels ( 7,1 vs 6,2 ng/ml; $\mathrm{p}<0,05$ ), higher PIRADS scores (PIRADS $\geq 428 \%$ vs $9 \%, p<0,05$ ) and lower prostate volumes (39 vs $45 \mathrm{cc}, \mathrm{p}<0,05$ ). No significant difference in iXip values was recorded when comparing patients with and without HG-PCa diagnosis. (Table 2). More specifically median iXip in high grade PCa patients was 0,31 vs 0,32 in low grade patietns $(\mathrm{p}=0,802)$.

On univariate binary logistic regression analysis age $(1,03: 0,99-1,08 ; p=0,001)$, PSA (1,04: $0,97-1,10 ; p=0,001)$, PV $(0,97: 0,95-0,99 ; p=0,013)$ and PIRADS score $(3,17$ : $2,05-4,91 ; \mathrm{p}=0,001)$ were predictors of HG-PCa. On multivariate binary logistic regression only age $(1,06: 1,01-1,12 ; \mathrm{p}=0,029)$, DRE $(2,56: 1,65-5,74 ; \mathrm{p}=0,001)$, PV( 0,96:0,94-0,98; $\mathrm{p}=0,012)$ and PIRADS score $(3,02: 1,93-4,71, \mathrm{p}=0,001)$ was an independent predictor of HG-PCa. (Table 3)

On ROC analysis iXip presented an AUC of 0,54 in the prediction of $\mathrm{HG}-\mathrm{PCa}$ (Epstein $\geq 3$ ). (Figure 1)

\section{DISCUSSION}

In the present study we evaluated the role of iXip in patients at increased risk of PCa. According to our results the iXip should not be used in the detection of PCa. Our results suggest that iXip is no more precise than a flip coin $(\mathrm{AUC}=0,57)$. Moreover, in our study we confirmed the predictive accuracy of PSA, prostate volume and PIRADS score. Our results are in line with the peer reviewed literature confirming the internal validity of our results ${ }^{20-23}$. 
In the past years, immunology studies have postulated the hypothesis of an immunogenic response to carcinogenesis ${ }^{24}$. Immunosurveillance processes by native or adaptive immune effectors is able to destroy cancer cells before they become clinically apparent ${ }^{24}$. However, in some cases the immune response is eluded by the tumour. Tumour antigens may then form immune complexes with $\operatorname{IgG}$ and $\operatorname{IgM}$ and more specifically these immunocomplexes have been reported in colon and breast cancer studies (CEA, TA90 and MUC-1 immune complexes) $)^{25-27}$.

The use of PSA immune complexes to detect PCa was initially introduced by Beneduce et al in $2007^{15}$. In their study they evaluated the presence of PSA-immune complexes in patients with $\mathrm{PCa}$ and in patients with $\mathrm{BPH}$. The first interesting observation was that healthy control patients presented a complete absence of PSA-immune complexes. Moreover, they observed a prevalence of PSA immune complexes in PCa patients when compared with BPH patients (40\% vs $12 \%$; cut-off: 0,15 ). In their experience PSA immune-complexes presented an accuracy of 0,69 on ROC analysis and a specificity of $88 \%$ when applying a cutoff of $0,15^{15}$ The authors concluded that PSA-IgM complex could be a complementary serological marker for PCa.

Thereafter in 2013, Gallotta et al introduced the iXip algorythm to predict $\mathrm{PCa}$ in a cohort of 160 patients at risk of PCa. According to their results, iXip presented an estimated accuracy of 0,78 for the prediction of $\mathrm{PCa}^{14}$. As well, in 2018 Galosi et al evaluated in a biopsy cohort study the role of iXip for the prediction of PCa. They concluded that when iXip is inferior to 0,2 patients can safely omit prostate biopsy. Our results are not in line with these experiences and therefore larger multicenter trials should better evaluate the accuracy of iXip in the prediction of PCa. Antonelli et al in a recent review introduced an ongoing prospective study (PROXIMA study) in a radical prostatectomy cohort which should elucidate the controversial results on this topic ${ }^{13}$. 
In the past years, several tests have been proposed to overcome the common limitations of PCa diagnosis. According the EAU guidelines possible serum markers(i.e:Prostate health index (PHI) and 4Kallicrein score) are recommended in the diagnostic pathway of patients at increased risk of $\mathrm{PCa}^{28}$. Moreover, urinary markers may help as well in the diagnostic workup (PCa3, Select MDX, Mi prostate score and Exodx) ${ }^{29}$. Although these biomarkers have good accuracies in the detection of PCa, their use is limited by availability and costs.

A possible alternative, according to the guidelines, is the use of calculators which can combine different variables to establish the risk of cancer and high-grade PCa. These calculators are available as nomograms, computer programs or mobile phone Apps. Several studies have evaluated different calculators and it is advisable to use calculators based on populations which reflect the local population. However, the most updated risk calculator is the ERSPC Rotterdam app which includes: previous biopsies, DRE, PV, PSA, PIRADS score, and PHI score ${ }^{30-34}$.

In 2019 the EAU guidelines based on several trials (PRECISION, MRI-FIRST...) recommended the use of MRI in all patients at increased risk of $\mathrm{PCa}^{35,36}$. The use of MRI in first set biopsies improves the detection of clinically significant cancer and is cost effective. In line with the peer reviewed literature in our study PIRADS score was an independent predictor of $\mathrm{PCa}^{376}$.

The present study has the merit of including MRI data in the evaluation of the predictive accuracy of iXip for the first time. In a separate analysis to evaluate the correlation between PIRADS score and iXip values we observed the lack of correlation between these two parameters (data not shown). This result is not surprising and is in line with the lack of correlation between PCa and iXip. Standing to the available literature, before its clinical implementation iXip test clearly needs multi-center validation. 
We have to acknowledge some limitations to our study. This is a small single center experience, so the results clearly depend on the enrolled population. We certainly acknowledge that it takes more than one study and one cohort of patients to prove a hypothesis. PCa epidemiology presents large differences due to racial, and geographical issues that need to be explored ${ }^{38,39}$. We have performed the study in a southern European cohort of patients that may be different from northern European, North American, South American and Asian populations. Another limitation, common to most studies in this area, derives from the use of biopsy cohorts without radical prostatectomy specimens confirmation. Notwithstanding all these limitations our study adds important evidence on the role of PSA immune complexes in the prediction of PCa.

\section{CONCLUSIONS}

According to our results, iXip should not be part of the diagnostic work out in patients at increased risk of PCa. In the presence of MRI data iXip adds no information in the decision making of patients at increased risk of PCa. Further multicenter studies should clarify its role in clinical practice.

\section{Clinical significance}

- Several studies have evaluated the role of complexes between cancer specific biomarkers and $\operatorname{IgM}$ in Prostate Cancer diagnosis

- These immune-complexes have been included in an algorithm to generate the index iXip, which determines the probability of having PCa. 
- Aim of our study was to evaluated the performance of iXip in the prediction of prostate cancer

- Our results suggest that iXip is no more precise than a flip coin, and we confirmed the predictive accuracy of PSA, prostate volume and MRI

- iXip should not be part of the diagnostic workout in patients at risk of PCa.

\section{Conflict of Interest:}

The authors reports no conflict of interest

\section{Funding}

None

\section{Acknowledgment}

None 


\section{References}

1. Kim JS, Ryu J-G, Kim JW, et al: Prostate-Specific Antigen fluctuation: what does it mean in diagnosis of prostate cancer? Int. Braz J Urol 41: 258-64.

2. De Nunzio C, Lombardo R, Tema G, et al: External validation of Chun, PCPT, ERSPC, Kawakami, and Karakiewicz nomograms in the prediction of prostate cancer: A single center cohort-study. Urol. Oncol. Semin. Orig. Investig. 2018; 36: 364.e1-364.e7.

3. Thompson IM, Ankerst DP, Chi C, et al: Assessing prostate cancer risk: Results from the Prostate Cancer Prevention Trial. J. Natl. Cancer Inst. 2006.

4. Catalona WJ, Richie JP, Ahmann FR, et al: Comparison of Digital Rectal Examination and Serum Prostate Specific Antigen in the Early Detection of Prostate Cancer: Results of a Multicenter Clinical Trial of 6,630 Men. J. Urol. 2017.

5. Wagenlehner FME, Van Oostrum E, Tenke P, et al: Infective complications after prostate biopsy: Outcome of the Global Prevalence Study of Infections in Urology (GPIU) 2010 and 2011, A prospective multinational multicentre prostate biopsy study. Eur. Urol. 2013.

6. Kuru TH, Saeb-Parsy K, Cantiani A, et al: Evolution of repeat prostate biopsy strategies incorporating transperineal and MRI-TRUS fusion techniques. World J. Urol. 2014; 32: 
945-950.

7. Brassetti A, Lombardo R, Emiliozzi P, et al: Prostate-specific Antigen Density Is a Good Predictor of Upstaging and Upgrading, According to the New Grading System: The Keys We Are Seeking May Be Already in Our Pocket. Urology 2017.

8. De Nunzio C, Presicce F and Tubaro A: Inflammatory mediators in the development and progression of benign prostatic hyperplasia. Nat. Rev. Urol. 2016; 13: 613-626.

9. Salinas FA and Wee KH: Prognostic and pathogenetic implications of immune complexes in human cancer. Adv. Immun. Cancer Ther. 1986.

10. Dass TK, Aziz M and Ashok A: Prognostic Significance of Circulating Immune Complexes in Cancer Patients. Japanese J. Cancer Res. 1991; 82: 1284-1291.

11. Parveen S, Taneja N, Bathi R, et al: Evaluation of circulating immune complexes and serum immunoglobulins in oral cancer patients - A follow up study. Indian J. Dent. Res. 2010; 21: 10-15.

12. Steele G, Lahey S, Rodrick M, et al: Circulating immune complexes in patients with colorectal cancer. Am. J. Surg. 1983; 145: 549-553.

13. Antonelli A, Francavilla S, Gallotta A, et al: Current evidence and future perspectives about the role of ixip in the diagnosis of prostate cancer. Minerva Urol. e Nefrol. 2019; 71: 201-204.

14. Gallotta A, Ziglioli F, Ferretti S, et al: A novel algorithm for the prediction of prostate cancer in clinically suspected patients. Cancer Biomarkers 2013; 13: 227-234.

15. Beneduce L, Prayer-Galetti T, Giustinian AMG, et al: Detection of prostate-specific antigen coupled to immunoglobulin M in prostate cancer patients. Cancer Detect. Prev. 2007; 31: 402-407. 
16. Cicione A, De Nunzio C, Manno S, et al: An update on prostate biopsy in the era of magnetic resonance imaging. Minerva Urol. Nefrol. 2018; 70: 264-274.

17. Trucchi A, De Nunzio C, Mariani S, et al: Local anesthesia reduces pain associated with transrectal prostatic biopsy: A prospective randomized study. Urol. Int. 2005.

18. De Nunzio C, Trucchi A, Miano R, et al: The Number of Cores Positive for High Grade Prostatic Intraepithelial Neoplasia on Initial Biopsy is Associated With Prostate Cancer on Second Biopsy. J. Urol. 2009.

19. De Nunzio C, Pastore AL, Lombardo R, et al: The new Epstein gleason score classification significantly reduces upgrading in prostate cancer patients. Eur. J. Surg. Oncol. 2018.

20. De Nunzio C, Lombardo R, Presicce F, et al: Transrectal-ultrasound prostatic biopsy preparation: Rectal enema vs. mechanical bowel preparation. Cent. Eur. J. Urol. 2015;

68.

21. De Nunzio C, Tema G, Lombardo R, et al: Cigarette smoking is not associated with prostate cancer diagnosis and aggressiveness: a cross sectional Italian study. Minerva Urol. Nefrol. 2018; 70: 598-605.

22. De Nunzio C, Lombardo R, Tema G, et al: External validation of Chun, PCPT, ERSPC, Kawakami, and Karakiewicz nomograms in the prediction of prostate cancer: A single center cohort-study. Urol. Oncol. Semin. Orig. Investig. 2018.

23. De Nunzio C, Presicce F, Lombardo R, et al: Physical activity as a risk factor for prostate cancer diagnosis: A prospective biopsy cohort analysis. BJU Int. 2016; 117: E29-E35.

24. Zitvogel L, Tesniere A and Kroemer G: Cancer despite immunosurveillance: Immunoselection and immunosubversion. Nat. Rev. Immunol. 2006. 
25. Fuchs $\mathrm{C}$, Krapf F, Kern P, et al: CEA-containing immune complexes in sera of patients with colorectal and breast cancer - analysis of complexed immunoglobulin classes. Cancer Immunol. Immunother. 1988.

26. Habal N, Gupta RK, Bilchik AJ, et al: TA90-IC, a new marker for advanced colon cancer. Ann. Surg. Oncol. 2000.

27. Croce M V., Isla-Larrain MT, Demichelis SO, et al: Tissue and serum MUC1 mucin detection in breast cancer patients. Breast Cancer Res. Treat. 2003.

28. Mottet N, Bellmunt J, Bolla M, et al: EAU-ESTRO-SIOG Guidelines on Prostate Cancer. Part 1: Screening, Diagnosis, and Local Treatment with Curative Intent. Eur. Urol. 2017; 71: 618-629. Available at: http://www.ncbi.nlm.nih.gov/pubmed/27568654, accessed August 10, 2017.

29. Gadzinski AJ and Cooperberg MR: Prostate cancer markers. In: Cancer Treatment and Research.Vol 175. Springer International Publishing 2018; pp 55-86.

30. Pereira-Azevedo N, Osório L, Fraga A, et al: Rotterdam Prostate Cancer Risk Calculator: Development and Usability Testing of the Mobile Phone App. JMIR Cancer 2017; 3: e1. Available at: http://www.ncbi.nlm.nih.gov/pubmed/28410180, accessed January 19, 2018.

31. De Nunzio C, Lombardo R, Tema G, et al: Mobile phone apps for the prediction of prostate cancer: External validation of the Coral and Rotterdam apps. Eur. J. Surg. Oncol. 2019; 45: 471-476. Available at: http://www.ncbi.nlm.nih.gov/pubmed/30343993, accessed April 3, 2020.

32. De Nunzio C, Albisinni S, Freedland SJ, et al: Abdominal obesity as risk factor for prostate cancer diagnosis and high grade disease: A prospective multicenter italian 
cohort study. Urol. Oncol. Semin. Orig. Investig. 2013.

33. De Nunzio C, Albisinni S, Presicce F, et al: Serum levels of chromogranin A are not predictive of high-grade, poorly differentiated prostate cancer: Results from an Italian biopsy cohort. Urol. Oncol. Semin. Orig. Investig. 2014.

34. Brassetti A, Lombardo R, Emiliozzi P, et al: Prostate-specific Antigen Density Is a Good Predictor of Upstaging and Upgrading, According to the New Grading System: The Keys We Are Seeking May Be Already in Our Pocket. Urology 2018.

35. Merrett C, Mannas M, Black PC, et al: Magnet Before the Needle Commentary on: MRItargeted or Standard Biopsy for Prostate-cancer Diagnosis (PRECISION Trial). Urology 2018; 118: 1-2. Available at: http://www.ncbi.nlm.nih.gov/pubmed/29730255, accessed April 3, 2020.

36. Ahmed HU, El-Shater Bosaily A, Brown LC, et al: Diagnostic accuracy of multi-parametric MRI and TRUS biopsy in prostate cancer (PROMIS): a paired validating confirmatory study. Lancet 2017; 389: 815-822.

37. Kuru TH, Saeb-Parsy K, Cantiani A, et al: Evolution of repeat prostate biopsy strategies incorporating transperineal and MRI-TRUS fusion techniques. World J. Urol. 2014.

38. Jindal T, Kachroo N, Sammon J, et al: Racial differences in prostate-specific antigenbased prostate cancer screening: State-by-state and region-by-region analyses. Urol. Oncol. 2017; 35: 460.e9-460.e20. Available at: http://linkinghub.elsevier.com/retrieve/pii/S1078143917300583, accessed August 10, 2017.

39. Singh GK and Jemal A: Socioeconomic and Racial/Ethnic Disparities in Cancer Mortality, Incidence, and Survival in the United States, 1950-2014: Over Six Decades of Changing 
Patterns and Widening Inequalities. J. Environ. Public Health 2017; 2017: 2819372.

Available at: https://www.hindawi.com/journals/jeph/2017/2819372/, accessed August 10, 2017.

Table 1: General Characteristics of the cohort population

\begin{tabular}{|l|c|}
\hline & Median (IQR) \\
\hline Age (years) & $66(59 / 72)$ \\
\hline PSA (ng/ml) & $6,0(4,5 / 8,8)$ \\
\hline DRE & $42(26 \%)$ \\
\hline PIRADS score & \\
1 & $48(30 \%)$ \\
2 & $8(5 \%)$ \\
3 & $57(36 \%)$ \\
4 & $34(21 \%)$ \\
5 & $13(8 \%)$ \\
\hline iXip & $0,31(0,26 / 0,52)$ \\
\hline Prostate Volume $(\mathrm{ml})$ & $50(38 / 62)$ \\
\hline Number of cores & $18(16 / 22)$ \\
\hline
\end{tabular}

Table 2: General Characteristics of the cohort population according to cancer status

\begin{tabular}{|c|c|c|c|c|c|c|}
\hline$\nabla$ & No Cancer & Cancer & $p$ & $\begin{array}{l}\text { Low } \\
\text { Grade }\end{array}$ & $\begin{array}{l}\text { High } \\
\text { Grade }\end{array}$ & $p$ \\
\hline & $\begin{array}{c}93 / 160 \\
(58 \%)\end{array}$ & $\begin{array}{c}67 / 160 \\
(42 \%)\end{array}$ & & $\begin{array}{c}22 / 160 \\
(13 \%)\end{array}$ & $\begin{array}{c}45 / 160 \\
(28 \%)\end{array}$ & \\
\hline Age (years) & $\begin{array}{c}64 \\
(58 / 68) \\
\end{array}$ & $\begin{array}{c}71 \\
(60 / 75) \\
\end{array}$ & 0,001 & $\begin{array}{c}68 \\
(61 / 72) \\
\end{array}$ & $\begin{array}{c}70 \\
(60 / 74) \\
\end{array}$ & 0,098 \\
\hline DRE & $16(17 \%)$ & 23 (34\%) & 0,001 & $15(9 \%)$ & 21 (46\%) & 0,001 \\
\hline PSA (ng/ml) & $\begin{array}{c}5,7 \\
(4,0 / 8,4)\end{array}$ & $\begin{array}{c}6,8 \\
(4,7 / 10)\end{array}$ & 0,001 & $\begin{array}{c}6,2 \\
(5,3 / 7,5)\end{array}$ & $\begin{array}{c}7,1 \\
(4,8 / 9,6)\end{array}$ & 0,062 \\
\hline
\end{tabular}




\begin{tabular}{|l|c|c|c|c|c|c|}
\hline PIRADS $\geq 4$ & $\begin{array}{c}17 / 70 \\
(24 \%)\end{array}$ & $\begin{array}{c}15 / 52 \\
(29 \%)\end{array}$ & 0,020 & $2 / 22(9 \%)$ & $\begin{array}{c}13 / 45 \\
(28 \%)\end{array}$ & 0,001 \\
\hline iXip & 0,29 & 0,33 & 0,182 & 0,32 & 0,31 & 0,802 \\
$(0,26 / 0,57)$ & $(0,28 / 0,53)$ & & $(0,26 / 0,71)$ & $(0,28 / 0,50)$ & \\
\hline $\begin{array}{l}\text { Prostate } \\
\text { Volume (cc) }\end{array}$ & 53 & 40 & 0,001 & $\begin{array}{c}45 \\
(38 / 55)\end{array}$ & $\begin{array}{c}39 \\
(30 / 53)\end{array}$ & 0,001 \\
\hline $\begin{array}{l}\text { Number of } \\
\text { cores }\end{array}$ & $19 / 65)$ & $(30 / 59)$ & & $\begin{array}{c}18 \\
(19 / 23)\end{array}$ & $\begin{array}{c}17 \\
(15 / 19)\end{array}$ & 0,343 \\
\hline
\end{tabular}

Table3: Uni-variate and multivariate analysis

\begin{tabular}{|c|c|c|c|c|c|c|c|c|}
\hline & \multicolumn{4}{|c|}{ Cancer Model } & \multicolumn{4}{|c|}{ High Grade Model } \\
\hline & Univariate & $p$ & $\begin{array}{c}\text { Multivariat } \\
\mathrm{e}\end{array}$ & $p$ & Univariate & $p$ & Multivariat & $p$ \\
\hline Age & $\begin{array}{c}1,07 \\
(1,02- \\
1,12) \\
\end{array}$ & $\begin{array}{c}0,00 \\
1\end{array}$ & $\begin{array}{c}1,06 \\
(1,01-1,11)\end{array}$ & $\begin{array}{c}0,02 \\
4\end{array}$ & $\begin{array}{c}1,03 \\
(1,00- \\
1,08) \\
\end{array}$ & $\begin{array}{c}0,00 \\
5\end{array}$ & $\begin{array}{c}1.06 \\
(1,01-1,12)\end{array}$ & $\begin{array}{c}0,02 \\
9\end{array}$ \\
\hline DRE & $\begin{array}{c}2.03(1.10- \\
4.49)\end{array}$ & $\begin{array}{c}0,00 \\
1 \\
\end{array}$ & $\begin{array}{c}2,34 \\
(1,25-4,01)\end{array}$ & $\begin{array}{c}0,00 \\
1 \\
\end{array}$ & $\begin{array}{c}2.71(1.28- \\
5.74)\end{array}$ & $\begin{array}{c}0,00 \\
1 \\
\end{array}$ & $\begin{array}{c}2.56(1.65- \\
5.74) \\
\end{array}$ & $\begin{array}{c}0,00 \\
1 \\
\end{array}$ \\
\hline PSA & $\begin{array}{c}1,06 \\
(1,01 / 1,11 \\
)\end{array}$ & $\begin{array}{c}0,00 \\
1\end{array}$ & $\begin{array}{c}1,05 \\
(1,02-1,22)\end{array}$ & 0,03 & $\begin{array}{c}1,04 \\
(0,97 / 1,10 \\
1\end{array}$ & $\begin{array}{c}0,87 \\
5\end{array}$ & & \\
\hline $\begin{array}{l}\text { PIRADS } \\
\text { score }\end{array}$ & $\begin{array}{l}\quad 2,68 \\
(1,22- \\
5,89)\end{array}$ & $\begin{array}{c}0,02 \\
3\end{array}$ & 2,45 & $\begin{array}{c}0,01 \\
3\end{array}$ & $\begin{array}{c}3,17 \\
(2,05- \\
4,91) \\
\end{array}$ & $\begin{array}{c}0,00 \\
1\end{array}$ & $\begin{array}{c}3,02 \\
(1,93-4,71)\end{array}$ & $\begin{array}{c}0,00 \\
1\end{array}$ \\
\hline iXip & $\begin{array}{c}1,00 \\
(0,99 / 1,01 \\
)\end{array}$ & $\begin{array}{c}0,35 \\
4\end{array}$ & & & $\begin{array}{c}0,99 \\
(0,97 / 1,01 \\
)\end{array}$ & $\begin{array}{c}0,51 \\
8\end{array}$ & & \\
\hline $\begin{array}{l}\text { Prostat } \\
\text { e } \\
\text { Volume }\end{array}$ & $\begin{array}{c}0,98 \\
(0,96 / 0,99 \\
)\end{array}$ & $\begin{array}{c}0,01 \\
9 \\
\end{array}$ & $\begin{array}{c}0,97 \\
(0,95-0,99)\end{array}$ & $\begin{array}{c}0,01 \\
2\end{array}$ & $\begin{array}{c}0,97 \\
(0,95- \\
0,99) \\
\end{array}$ & $\begin{array}{c}0,01 \\
6\end{array}$ & $\begin{array}{c}0,96 \\
(0,94-0,98)\end{array}$ & $\begin{array}{c}0,01 \\
2\end{array}$ \\
\hline $\begin{array}{l}\text { Number } \\
\text { of cores }\end{array}$ & $\begin{array}{c}0,96 \\
(0,87 / 1,06 \\
\end{array}$ & $\begin{array}{c}0,43 \\
0\end{array}$ & & & $\begin{array}{c}0,90 \\
(0,87 / 1,15 \\
)\end{array}$ & $\begin{array}{c}0,34 \\
3\end{array}$ & & \\
\hline
\end{tabular}

Figure 1- ROC Curve 

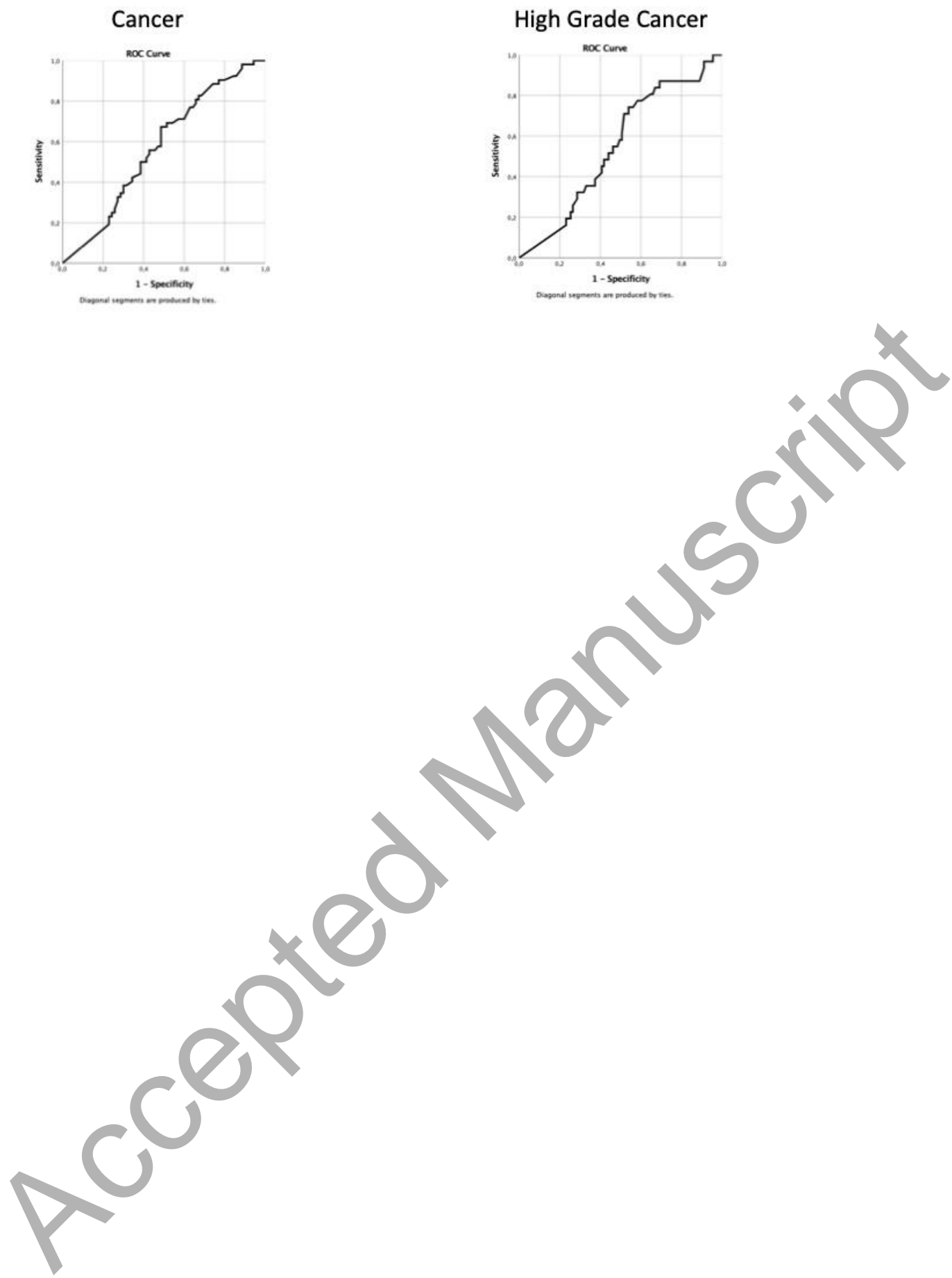


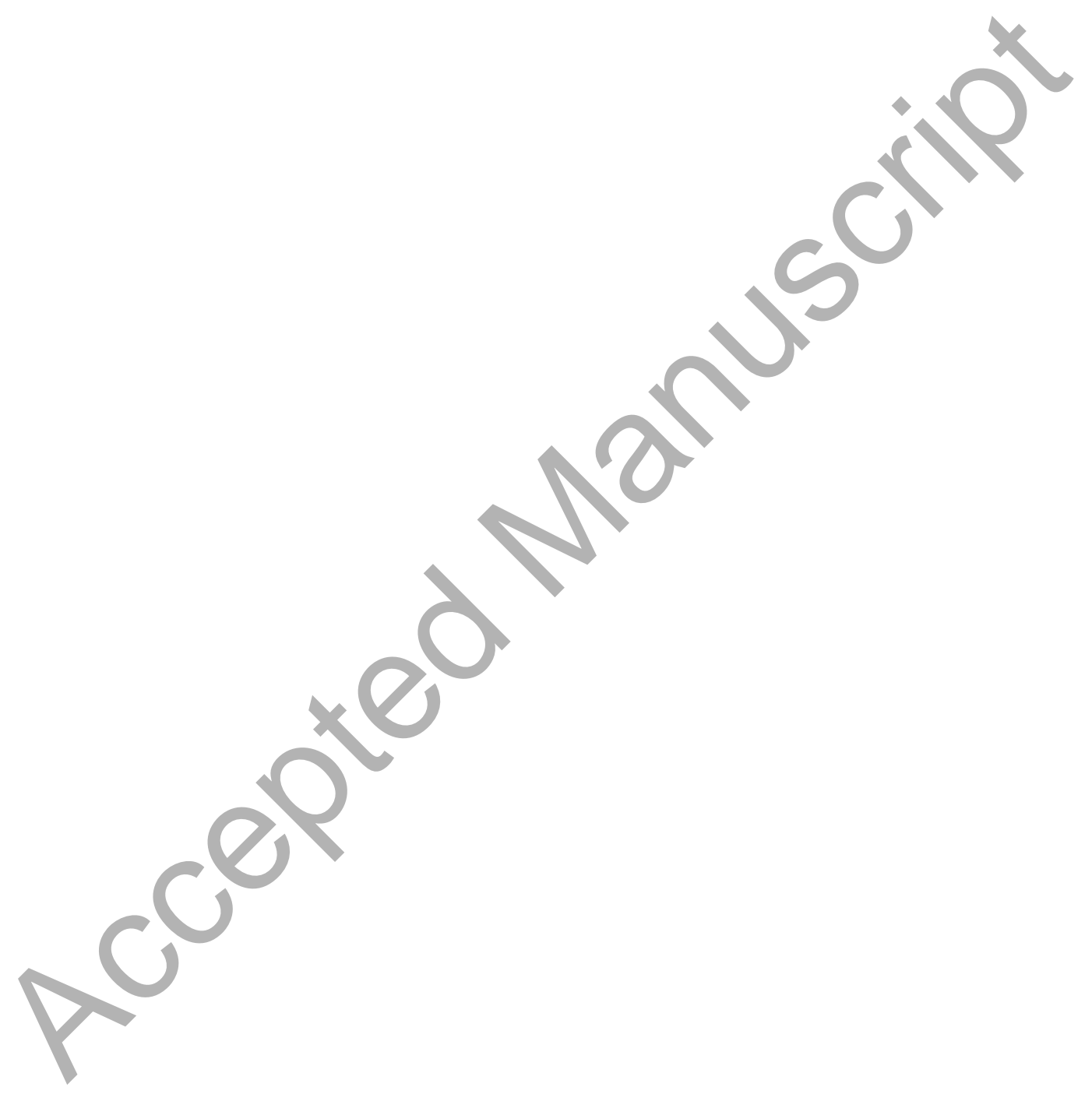

